\title{
Políticas públicas e participação social feminina: a experiência dos Conselhos Municipais de Desenvolvimento Rural Sustentável
}

\author{
Cleonice Borges de Souza \\ Mestre em Agronegócios - UFG \\ cleoniceborges@hotmail.com
}

\begin{abstract}
Resumo O artigo perscruta os Conselhos Municipais de Desenvolvimento Rural Sustentável dos municípios Bela Vista de Goiás e de Silvânia, no estado de Goiás, analisando a participação dos agricultores e agricultoras familiares no processo decisório e na operacionalização das políticas públicas para o meio rural. Os Conselhos envolvem relações sociais perpassadas por conflitos e disputas, com predomínio da participação social masculina em detrimento da feminina com evidências de marginalização da mulher no meio rural brasileiro. Este estudo analisa as relações sociais que se estabelecem entre os diversos agentes sociais que participam desses Conselhos com enfoque especial às relações de gênero.
\end{abstract}

Palavras-chave: políticas públicas; conselhos gestores; participação social; gênero.

\section{Introdução}

$\mathrm{O}$ Programa Nacional de Fortalecimento da Agricultura Familiar (Pronaf), instituído pelo Governo Federal em 1996, é a principal política pública destinada a apoiar os agricultores familiares. Segundo (Abramovay apud Schneider; Cazella; Mattei; 2004), o surgimento do Pronaf representou, por parte do Estado, o reconhecimento de que os agricultores familiares são também protagonistas das políticas públicas, instituindo um processo de negociação entre os agricultores e suas organizações e o Governo. Outro aspecto inovador dessa política pública, foi o estabelecimento de um enfoque territorial, ressaltando-se o papel dos Conselhos Municipais de Desenvolvimento Rural Sustentável (CMDRS), criados por demanda do Pronaf Infra-Estrutura e Serviços Municipais.

Os CMDRS, constituídos por agricultores e agricultoras familiares, representantes do poder público e de entidades parceiras, tornaram-se espaços institucionalizados de discussões e decisões de políticas públicas e, sobre o rumo e os caminhos que podem ser seguidos para melhorar as condições de vida da população rural.

Os CMDRS, na qualidade de espaços colegiados, são sistematicamente direcionados a manter sua objetividade na busca efetiva e legítima da gestão social, mediante uma ampla representatividade, diversidade e pluralidade dos diversos agentes sociais envolvidos nas diferentes dimensões do desenvolvimento rural (social, econômica, cultural, política e ambiental), cujo fundamento reside nos pressupostos da participação democrática.

Do ponto de vista formal, tem de fato ocorrido a presença majoritária dos agricultores familiares e/ou de seus representantes no interior dos 
Conselhos. Contudo, a mera paridade numérica não tem significado ou garantido a suposta simetria entre os atores integrantes dos Conselhos. $\mathrm{Na}$ arquitetura de relações de poder, a questão da paridade é, sem dúvida, relevante; todavia, a mera distribuição eqüitativa dos assentos entre os diferentes segmentos torna-se uma variável limitada para a compreensão de como essa configuração realmente está sendo operacionalizada. Isto é, a igualdade numérica por si só não garante e nem tem condições de garantir a eqüidade de capacidades e competências na definição e operacionalização das políticas públicas.

Alguns elementos apresentam-se como fatores que distinguem e hierarquizam a participação nos Conselhos, geralmente privilegiando os representantes do poder público, tanto do executivo municipal quanto das instituições oficiais de assistência técnica e extensão rural. Entre os quais, temos: a) custos de participação - estadia, transporte, alimentação e o próprio valor do dia de trabalho, entre outros - diretamente relacionados às disponibilidades financeiras e de tempo, tornam-se fatores determinantes; b) diferencial de recursos - os agricultores familiares em relação aos representantes governamentais são os que apresentam as menores possibilidades de acesso aos recursos; c) a posse de determinados conhecimentos técnicos, a compreensão do funcionamento da máquina administrativa, o domínio da capacidade argumentativa e a habilidade no seu uso, entre outros, são instrumentos que favorecem a negociação num mesmo patamar de paridade (Moruzzi Marques, 2004; Tommasi, 1997).

Nessa perspectiva, os Conselhos emergem como espaços sociais específicos perpassados por conflitos e por relações de poder entre os diferentes agentes sociais que deles participam. Esses espaços são marcados por intensa luta simbólica e pela afirmação de distintas estratégias de poder pelos agentes sociais. A igualdade não passa de um fetiche, de algo inalcançável.

Dessa forma, este trabalho tem por premissa analisar as relações sociais que se estabelecem entre os diversos agentes sociais que participam do espaço social específico: CMDRS, bem como as relações de gênero que se configuram neste espaço social, visto a predominância dos agricultores em detrimento das agricultoras. Têm como objetivos específicos: cartografar os diferentes sujeitos sociais que compõem esses espaços sociais; analisar as práticas sociais internas aos conselhos, procurando deslindar os jogos de força, os conflitos, as formas de imposição de concepções e interesses; analisar os impasses, as dificuldades, as desigualdades que se impõem à plena participação nos conselhos, em especial os custos de participação: custos materiais (tempo livre, estadia, transporte, alimentação...) e custos simbólicos (competências, saberes etc.).

Buscou-se conhecer a realidade empírica dos municípios de Bela Vista de Goiás e de Silvânia, tomados como amostra em uma totalidade de quatorze municí- pios que compõem o Território Estrada de Ferro (TEF), no Estado de Goiás. A análise sobre os Conselhos teve por fundamento buscar dar visibilidade e inteligibilidade sociológica às relações de poder que se estabelecem neste espaço social, por meio das ações, comportamentos e situações vivenciados por seus agentes, com destaque para as relações sociais de gênero.

Para o levantamento dos dados utilizei-me de técnicas de investigação qualitativas (realização de entrevistas, pesquisa documental e observação assistemática) e quantitativas (aplicação de questionários e análise de relatórios estatísticos).

Dos quatorze municípios que compõem o TEF, até o mês de setembro de 2006, quando do início do levantamento dos dados, somente onze já haviam instituído seus conselhos e destes apenas sete (Bela Vista de Goiás, Caldazinha, Gameleira de Goiás, Orizona, Palmelo, Silvânia e Vianópolis) estavam realizando suas atividades, nos quais foi possível realizar uma caracterização e o nível de participação sociopolítica desses agentes. Contudo, no decorrer da realização da pesquisa de campo, entre setembro de 2006 e fevereiro de 2007, foram instituídos os três Conselhos que estavam pendentes de instituição (Bonfinópolis, Cristianópolis e Urutaí), bem como, retomaram suas atividades os Conselhos que estavam desativados (Leopoldo de Bulhões, Pires do Rio, Santa Cruz de Goiás e São Miguel do Passa Quatro), possibilitando cartografar todos os agentes sociais partícipes dos Conselhos do TEF.

\section{Território estrada - contextualização}

O Território Estrada de Ferro está localizado na porção Centro-Leste do Estado de Goiás e ocupa uma área de $11.623,946 \mathrm{~km}^{2}$, o que equivale a $3 \% \mathrm{da}$ área total do Estado (MDA, 2005).

Seus municípios estão distribuídos em duas microrregiões: Goiânia e Pires do Rio. Na primeira, estão localizados os municípios de Bela Vista de Goiás, Bonfinópolis, Caldazinha e Leopoldo de Bulhões. Na microrregião de Pires do Rio estão Cristianópolis, Gameleira de Goiás, Orizona, Palmelo, Pires do Rio, Santa Cruz de Goiás, São Miguel do Passa Quatro, Silvânia, Urutaí e Vianópolis (Figura1).

Uma análise sucinta nos indicadores socioeconômicos do Território Estrada de Ferro resulta as seguintes informações:

a) População: Bela Vista, Orizona, Pires do Rio, Silvânia e Vianópolis são os municípios onde há a maior concentração populacional, acolhendo aproximadamente $73 \%$ dos 124.005 habitantes do Território e $68 \%$ dos 42.662 indivíduos que residem no meio rural (MDA, 2005); 


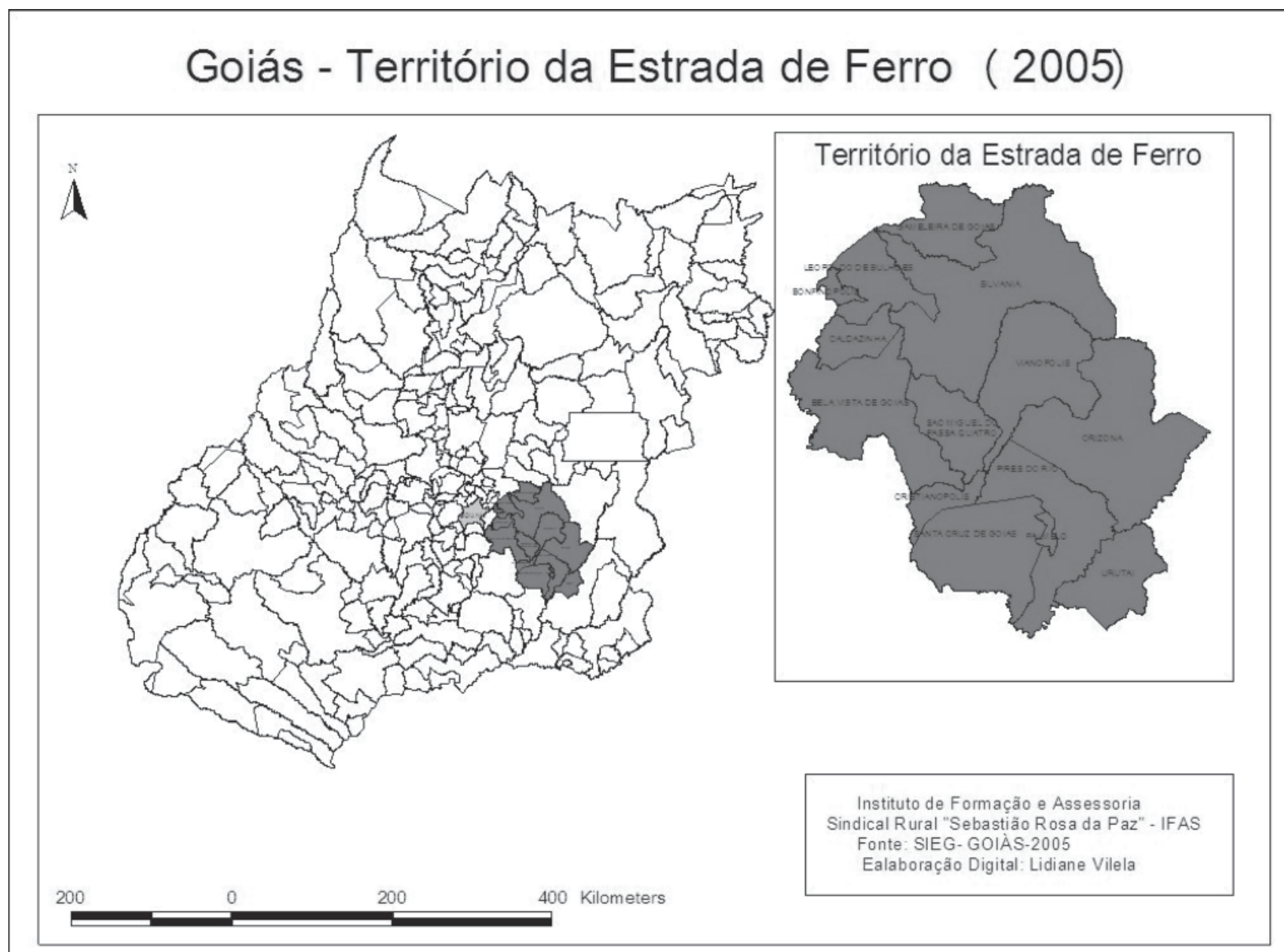

Figura 1: Mapa de localização do Território Estrada de Ferro

Fonte: MDA. Estudo propositivo do Território Estrada de Ferro - Goiás: versão preliminar, 2005, p. 6.

b) Indicadores de Desenvolvimento Humano (IDH): O IDH do Território Estrada de Ferro é 0,761, o qual mesmo estando abaixo das médias estadual $(0,776)$ e nacional $(0,766)$, é considerado, dentro dos parâmetros mundiais, um índice mediano. Quando procede-se à análise do IDH por componentes, o TEF apresenta os seguintes dados: longevidade $(0,753)$, educação $(0,845)$ e renda $(0,686)$, destacando-se em relação ao Estado no componente longevidade, cujo índice é de 0,745 (Seplan/Sepin, 2007);

c) Indicadores de Pobreza: Dos 35.851 domicílios existentes no TEF, 28,8\% (10.317) estão em situação de pobreza. O percentual de domicílios pobres do Território $(28,8 \%)$ supera em mais de oito pontos percentuais o estadual $(20,3 \%)$. Os domicílios pobres do TEF representam 3,6\% do conjunto do Estado (MDA, 2005).

d) Indicadores Econômicos: A produção animal e vegetal do Território Estrada de Ferro, em 2004, equivalente a $5 \%$ de toda a produção do Estado de Goiás, foi em valores absolutos igual a $\mathrm{R} \$ 129.345 .000,00$. A arrecadação de Imposto sobre a Circulação de Mercadorias e Serviços (ICMS) e a renda total mensais foram, respectivamente $\mathrm{R} \$ 24.540 .000,00$ e $\mathrm{R} \$ 30.218 .000,00$, e esta última, em valores relativos foi igual a 2,1\% de toda a renda total mensal do Estado (MDA, 2005).

De um total de 42.871 pessoas ocupadas em atividades econômicas no Território, praticamente 77\% foram absorvidas no campo (32.989), depreendendo-se desses números a enorme importância dos estabelecimentos rurais na geração e manutenção do emprego no campo. Os agricultores familiares presentes na maioria dos municípios que compõem o Território e, até mesmo no somatório total do próprio Território, apresentam as rendas totais, monetárias e não-monetárias superiores aos valores gerados pela agricultura patronal, o que revela sua capacidade de utilizar os recursos produtivos de forma mais eficiente que os patronais, pois mesmo detendo as menores áreas, produzem e empregam mais do que os agricultores patronais.

Da análise das informações apresentadas depreende-se a importância da agricultura familiar como estrutura eficiente e viável no contexto do setor agrícola do Território e do Estado de Goiás, especialmente pela produtividade alcançada em áreas, relativamente reduzidas, além da capacidade de geração de emprego e renda no meio rural. 


\section{Trabalho e gênero: a força da mulher no meio rural}

No contexto das recentes transformações por quem passando o meio rural e não obstante a agricultura familiar presente no Território Estrada de Ferro, a participação das mulheres nos processos produtivos aliada a uma redefinição desses processos, vem paulatinamente alcançando maior inserção e visibilidade socioeconômica.

Em Silvânia, a representante da Mulher Rural no Conselho Municipal de Desenvolvimento Rural Sustentável, que também é funcionária da Agenciarural ${ }^{1}$, nos relata que o trabalho desenvolvido pela Associação de Mulheres da comunidade a qual pertence está embasado na diversificação. Inicialmente, quando da fundação da Associação, esta foi fundada com o objetivo de subsidiar às mulheres da região a oferta de cursos de qualificação e capacitação para a produção de frango caipira melhorado, em função da perspectiva de construção de um abatedouro na sede do município de Silvânia, o qual seria responsável pelo abate de toda a produção de frangos dos quatorze municípios que compõem o Território.

Em função de problemas e atrasos na construção do abatedouro, as mulheres não tiveram condições de iniciar a criação dos frangos, então resolverem plantar mudas de eucalipto para comercializar. Logo, conseguiram algumas economias que seriam destinadas à construção do galpão para a criação dos frangos, o que foi rapidamente investido na Lavoura Comunitária, por meio da Central de Associações, da qual fazem parte. Durante três anos as mulheres se responsabilizaram por todas as atividades da Lavoura Comunitária, por meio da cultura do milho: roçaram, plantaram, adubaram, limparam, colheram, fizeram silo e comercializaram toda a produção.

Ainda no aguardo do abatedouro, resolveram investir em outra atividade, qual seja o artesanato. Por intermédio do Sindicato Rural (SR), contataram o Serviço Nacional de Aprendizagem Rural (SENAR) e realizaram os cursos necessários à confecção de colchas de retalhos, as quais eram comercializadas em Goiânia, Brasília e região do Território. Conseguiram firmar parceria com a Prefeitura Municipal de Silvânia, que doou uma máquina de costura, e com a Secretaria de Desenvolvimento Territorial (SDT), que viabilizou o projeto da confecção.

Quando da finalização da pesquisa de campo no Território, estava em fase final a construção do abatedouro com perspectivas de início de novos cursos de capacitação e qualificação para a produção de frango semicaipira, para todas as mulheres do Território.
No município de Bela Vista não houve oportunidade de entrevistarmos nenhuma mulher, visto que o processo de pesquisa foi realizado no âmbito dos CMDRS, e no âmbito deste município nenhuma mulher participou das reuniões durante o processo de pesquisa, tampouco têm mulheres como membros. Contudo, o relato dos homens presentes nesse Conselho é de que, similarmente ao que acontece em Silvânia, as mulheres participam ativamente do processo produtivo, sendo esse o motivo alegado por alguns homens - o excesso de atividades domésticas e rurais - um dos impedimentos à participação ativa das mulheres nos processos participativos e decisórios dos caminhos e direções às políticas públicas no meio rural.

Depreende-se daí, a força e a perspicácia das mulheres no contexto familiar e econômico de suas regiões. Contudo, como visto no início deste trabalho, a existência de fatores que distinguem e diferenciam a participação social representa o maior óbice à participação das mulheres agricultoras e, também, de boa parte dos agricultores nos espaços de debate e deliberação sobre o rumo e os caminhos que podem ser seguidos para melhorar a qualidade de vida da população no meio rural, quais sejam os Conselhos Municipais de Desenvolvimento Rural Sustentável.

\section{Conselho municipal de desenvolvimento rural sustentável: espaço de participação e conflito social}

A participação dos agricultores e agricultoras familiares, juntamente com o poder público, no processo decisório e na operacionalização das políticas públicas, abre novas perspectivas para o desenvolvimento local uma vez que permite que se tornem conhecidas as reais demandas dos agricultores familiares e, também, que as soluções delineadas sejam compatíveis com a realidade local.

Ainda que emuladores do jogo político democrático, os CMDRS são espaços que envolvem relações permeadas por conflitos e disputas de ordem social, política, econômica, cultural e ideológica em torno dos CMDRS nos municípios que compõem o TEF.

De um modo geral, todos os Conselhos Municipais de Desenvolvimento Rural Sustentável do Território Estrada de Ferro foram instituídos a partir de 1996, em função da necessidade de habilitar os municípios para que tivessem acesso aos recursos do Pronaf em sua linha de Infra-estrutura e Serviços Municipais. Conforme a nor- 
mativa do Programa, somente poderiam pleitear esses financiamentos os municípios que tivessem preponderância de agricultores familiares; que fossem selecionados anualmente pelo Conselho Nacional do Pronaf; e que possuíssem um Plano Municipal de Desenvolvimento Rural (PMDR) aprovado pelo respectivo CMDR.

Apesar da literatura ser unânime na constatação de que o Pronaf vem, paulatinamente, correspondendo a uma transformação significativa nas políticas públicas voltadas ao meio rural no Brasil, é possível constatar, também, que os conselhos que se formam estritamente como contrapartida à exigência legal para a obtenção de recursos públicos por parte dos municípios terminam não expressando uma dinâmica local significativa (Abramovay, 2003). Em muitos casos, o que se vê é sua utilização como espaço de legitimação e de redefinição dos mecanismos tradicionais de dominação de elites locais.

Um aspecto de muita relevância levantado na pesquisa diz respeito à forma como os Conselhos Municipais de Desenvolvimento Rural Sustentável do TEF foram instituídos. Dos 14 Conselhos analisados, constata-se, na análise documental, que todos eles foram instituídos por Lei Municipal, apontando para uma realidade bastante positiva, uma vez que a instituição dos conselhos por intermédio de lei garante-lhes maior legitimidade, pelo fato de decorrerem de aprovação e reconhecimento do Legislativo Municipal, possibilitando assim que se tornem mais estáveis e mais democráticos que os conselhos criados por decreto do poder executivo (Ipardes, 2001; Moruzzi Marques, 2004).

A disseminação de informações entre os conselheiros é considerada um dos pontos essenciais para o bom desempenho de suas funções. Contudo, no cotidiano esse repasse não tem ocorrido com a frequiência necessária. Em relação à forma de instituição dos CMDRS, entre os 48 conselheiros que preencheram os questionários, $66,7 \%$ informaram que os Conselhos haviam sido instituídos por Lei Municipal, 20,8\% por Decreto Municipal ou outras modalidades e 12,5\% disseram não saber como haviam sido instituídos os conselhos dos quais participam.

Questionados, ainda, sobre a existência de experiências anteriores ao Pronaf, que buscassem agregar os agentes sociais em torno da formulação e gestão de propostas para o desenvolvimento rural, tal como está previsto para os CMDRS, de um modo geral foi consenso entre a maioria dos conselheiros $(75 \%)$ de que não existiram, anteriormente, experiências com a mesma amplitude dos Conselhos, especialmente de congregação e organização dos agentes sociais em torno do desenvolvimento rural.

Do ponto de vista dos entrevistados, os depoimentos terminam corroborando essas informações:
Passou a incumbência que queria que todas organizações sentassem à mesma mesa pra discuti, que até então as organizações faziam as ações para o meio rural, mas não tinha uma discussão ampla. [...] Porque tinha o Sindicato que trabalhava com o produtor; tinha a Agenciarural; tinha a Cooperativa, que naquele momento tava se criando, tinha-se criado a Central de Associações, [...] fazia um trabalho com o produtor, mas não era conjunto. Nós tentávamos organizar, mas, nós não éramos, aqui, organizados (Entrevistado 5, ExConselheiro representante do Executivo Municipal, participou da instituição do CMDRS de Silvânia) ${ }^{2}$.

Percebe-se nesse contexto, uma reduzida presença de capital social na região. Não de capital social identificável em instituições (cooperativas, associações, sindicatos etc.), mas espelhada por "laços de solidariedade típicos das regiões onde houve convívio de populações no bojo de atividades produtivas que deram certo" (Guanziroli et al., 2001, p. 257). As forças sociais encontravam-se esparsas e as relações de parceria e confiança, que antes pareciam existir, agora encontravam-se abaladas, necessitando de mecanismos que dessem conta de desenvolver sinergias, mediante a mobilização de recursos e da criação de laços sociais com vistas à inovação e ao desenvolvimento.

Segundo Bourdieu (2002, p. 67),

o capital social é o conjunto de recursos atuais ou potenciais que estão ligados à posse de uma rede durável de relações mais ou menos institucionalizadas de interconhecimento e de inter-reconhecimento ou, em outros termos, à vinculação a um grupo, como conjunto de agentes que não somente são dotados de propriedades comuns (passíveis de serem percebidas pelo observador, pelos outros ou por eles mesmos), mas também são unidos por ligações permanentes e úteis. Essas relações são irredutíveis às relações objetivas de proximidade no espaço físico (geográfico) ou no espaço econômico e social porque são fundadas em trocas inseparavelmente materiais e simbólicas cuja instauração e perpetuação supõem o re-conhecimento dessa proximidade.

O conceito de capital social tem sido utilizado de forma freqüente para identificar o conjunto de relações (pessoais, sociais, institucionais) que, mobilizado por pessoas, organizações e movimentos visando a um determinado fim, é a um só tempo, baseado, e gerador de confiança, reciprocidade e cooperação. Entre os vários autores que utilizam a noção de capital social em seus trabalhos, chamo a atenção para Robert D. Putnam, autor do livro Comunidade e democracia: a experiência da Itália moderna. Para Putnam, 
o capital social diz respeito a características da organização social como confiança, normas e sistemas, que contribuem para aumentar a eficiência da sociedade, facilitando as ações coordenadas (Putnam, 1996, p. 177).

O autor busca mediante a medição do capital social por meio de indicadores e, sua posterior, correlação com índices de desenvolvimento econômico e institucional, comprovar que

só conseguem acumular capital social aqueles povos que já têm uma longa tradição de solidariedade, cooperação e associativismo. [...] Essa abordagem termina por enredá-lo numa tese inaceitável do ponto de vista sociológico, que defende a existência de um determinismo da história sobre a capacidade atual de organização de um povo. [...] O viés positivista de suas análises quantitativas e a seleção das variáveis estudadas, deixam de fora categorias centrais, processos sociais, como poder, conflitos, etnia, gênero, relações público-privado, privilegiando as variáveis com relações significativas do ponto de vista estatístico (Matos, 2005).

Assim, a relação de identidade grupal, como base da formação e da posse durável das relações sociais, pode ser mobilizada pelas pessoas, organizações e movimentos objetivando um fim específico. A ausência desse capital tem favorecido a subordinação e a dependência dos agentes locais às instâncias políticas locais e territoriais, em função de que as comunidades detentoras de um quantum de capital social mais elevado, terão uma maior capacidade e poder de confrontação com o poder dominante.

A eficiência dos Conselhos depende de sua composição e organização, cujos critérios devem estar definidos em suas leis de criação e em seus regimentos internos, ainda que, muitas vezes, de forma imprecisa e equivocada (Ipardes, 2003).

Segundo esta composição, é possível observar a existência de dois tipos de conselhos: de uma parte, os Conselhos que comportam todas as associações rurais constituídas na base territorial no município e, de outra parte, Conselhos que acolhem um número limitado de associações que representam um conjunto de comunidades.

Diferentemente do que ocorre em outras regiões do País (Moruzzi Marques, 2004), uma situação relativamente comum nos Conselhos do TEF é a presença dos Sindicatos Rurais. Normalmente tidos como representantes da agricultura patronal, em alguns Conselhos, no entanto, chegam a representar, até mesmo, os agricultores familiares. Aliás, é latente a falta de uma definição clara de quais entidades sejam representantes dos agricultores familiares e do poder público.

Em Bela Vista de Goiás, Caldazinha, Cristianópolis, Gameleira de Goiás, Leopoldo de Bulhões, Santa Cruz de Goiás, São Miguel do Passa Quatro, Urutaí e Vianópolis os agricultores familiares são representa- dos basicamente por suas associações e pelo Sindicato dos Trabalhadores Rurais - onde estes existem -, enquanto nos demais municípios (Orizona, Pires do Rio e Silvânia) o Sindicato Rural também aparece como representante dos agricultores familiares.

De outra forma, encontra-se em Gameleira de Goiás, a Mulher Rural como representante do Poder Público. Ou seja, configura-se a existência de um mix de possibilidades de composição dos Conselhos: se, por um lado, há a participação do STR, SR, Cooperativas, Central de Associações e Associação de Moradores, entre outros, como representantes de agricultores familiares; de outro, essas mesmas entidades, em outros municípios, aparecem como representantes do Poder Público.

Esta situação denota tanto a falta de observância às normas regimentais estabelecidas pelo Conselho Nacional de Desenvolvimento Rural Sustentável (Condraf), entidade responsável pela elaboração das normativas e diretrizes para as atividades a serem desenvolvidas pelo Conselho Nacional, pelos Conselhos Estaduais, pelos Conselhos Territoriais, pelas CIAT's e pelos Conselhos Municipais de Desenvolvimento Rural Sustentável -, quanto um indicativo da possibilidade de se estar usurpando o protagonismo proposto aos agricultores familiares, visto que os representantes do Poder Público então sendo detentores dos diferenciais de participação - conhecimento técnico e forma de funcionamento da burocracia administrativa, entre outros -, ao acoplarem junto a si os representantes sindicais, de cooperativas, de associações etc., estarão aumentando tanto em nível quantitativo quanto em qualitativo os diferenciais de poder do grupo em questão diante dos agricultores familiares, normalmente desprovidos dessas capacidades.

Contudo, um ponto que chama a atenção é a existência da paridade numérica entre os representantes da agricultura familiar e dos poderes públicos, presente em todos os Conselhos, e em alguns Conselhos o número de representantes da agricultura familiar é superior, como é o caso de Caldazinha, Leopoldo de Bulhões e São Miguel do Passa Quatro, com aproximadamente 55\% dos representantes sendo da agricultura familiar; Vianópolis com 57\%; Santa Cruz de Goiás com 60\%; e Pires do Rio e Urutaí com os percentuais mais elevados de representação para a agricultura familiar, aproximadamente $62 \%$.

Para que os Conselhos sejam espaços democráticos de participação não basta atender tão somente à exigência numérica de que, no mínimo 50\% dos assentos no CMDRS pertençam aos representantes dos agricultores familiares. A efetiva paridade envolve a aquisição de competência dos atores envolvidos, a qual se constrói em função do acesso às informações e às oportunidades de formação; do acesso aos recursos - conhecimentos, informacionais, de comunicação e relacionais - que possibilitam a construção do sentido e da possibilidade de serem sujeitos da própria ação (Tommasi, 1997). 
O aprendizado da participação, pelo conhecimento da máquina governamental, da capacidade de negociação e da convivência com outros setores sociais, é um processo demorado que deve ser estimulado e impulsionado, mediante uma vontade política que introduzir "mudanças de atitudes e valores, que apostem para uma nova cultura política democrática" (Tommasi, 1997, p. 94). De forma geral, o processo participativo nos Conselhos deve possibilitar aos participantes o aprendizado do exercício da democracia, da publicização e da transparência dos processos de decisão por parte do poder público.

\section{Conselhos $x$ gênero: prevalência masculina ou marginalização feminina?}

A tabulação dos questionários serviu para fundamentar uma questão relevante e que já havia sido observada empiricamente, qual seja: a esmagadora predominância de homens compondo os Conselhos. Dos 48 conselheiros que responderam aos questionários, 39 são homens $(81,2 \%)$ e apenas 9 são mulheres $(18,8 \%)$. Entre estas, somente 3 são agricultoras ou representam os agricultores familiares nestes Conselhos; as demais representam secretarias de saúde, educação, meio ambiente, Câmara de Vereadores e Agenciarural, áreas em que é mais comum a participação das mulheres, exceção feita somente à Agenciarural, onde tradicionalmente predominam as atividades extensionistas realizadas por homens.

Apesar da existência de uma representação formal da Mulher Rural, o reduzido número de mulheres entre os conselheiros pesquisados reflete uma inexpressiva representatividade feminina entre os membros dos CMDRS. Este aspecto torna-se mais evidente quando se analisa os dados gerais dos 14 Conselhos do TEF. De um total de 133 conselheiros, somente 26 são mulheres, número que não representa $20 \%$ do número total de membros dos CMDRS.

Chama a atenção a ausência, na maioria dos Conselhos, de instrumentos que favoreçam a presença das mulheres neste espaço social. Entre todos os Conselhos analisados, somente em dois (Silvânia e Gameleira de Goiás) tem-se um acento específico para esta categoria social: representante da Mulher Rural.

$\mathrm{O}$ ato da representação, de estar e de se sentir autorizado a falar dos representados e para os representados, constituí-se por si só, numa força nas lutas internas no campo social.

Um grupo só começa a existir enquanto tal, para os que fazem parte dele e para os outros, quando é dis- tinguido, segundo um princípio qualquer, dos outros grupos, isto é, através do conhecimento e do reconhecimento (Bourdieu, 1990, p. 168).

Assim, o fato de um agente social não se sentir legitimado para o exercício da função à qual foi escolhido, por não se sentir parte do grupo em questão, não o descaracteriza como possuidor dos atributos que lhe foram delegados para o exercício da função, ou seja, representar um grupo social específico: a Mulher Rural.

Não sei se eu seria a mulher ideal pá representar a mulher rural, porque eu tinha pouco tempo de zona rural. Mas como eu sou funcionária da Emater, digo da Agenciarural e conhecia bastante gente, tinha um trabalho antigamente com a Joana, e depois com Beatriz a gente tava sempre envolvida então, com as mulheres, achavam que eu tinha um perfil que adaptava nesse Conselho representando essas mulheres (Conselheira 2, representante da Mulher Rural, de Silvânia).

Contudo, não é uma estratégia que passa despercebida dos agentes sociais que participam do espaço social. Dentro da estrutura social dada, residem os questionamentos sobre essa representatividade. As estratégias discursivas dos diferentes agentes sociais, especialmente os efeitos retóricos que buscam produzir, dependem das relações de força simbólica presentes no espaço social ou de forma mais específica dos interesses em questão.

Não conheço nenhuma associação que ela participa. Pra começá, ela mora aqui na cidade, não mora na roça, se tá morando é agora de pouco. [...] Mais é um ano, um ano e pouco pra cá. Mais antes não era, só morava aqui dentro da cidade. E já era representante. Então, esses Conselhos é muito bom, mas são.... eu por todos os Conselhos que eu já conversei, a maioria são Conselho muito assim, tendencioso que não tem uma, uma...condição assim, vamo falá autônoma nas decisão (Conselheiro 1, representante do STR de Silvânia).

Essas falas refletem conflitos internos à representação da agricultura familiar: o aparente processo de desqualificação simbólica da mulher, nada mais é do que uma contestação do sindicalista em relação à agente social representante da Mulher Rural, que também é técnica do Estado. Conforme seu ponto de vista, a presença da Mulher Rural no Conselho, da forma como está colocada, funciona como uma estratégia dos grupos dominantes manterem-se no poder.

Segundo avaliação realizada pelo Ipardes (2001), uma das principais características da agricultura familiar é a participação determinante e maciça das mulheres, lado a lado com os homens. Contudo, o espaço para participar das decisões coletivas tem se mantido restrito aos homens. 


\section{Custos de participação}

Os Conselhos, espaços de gestão social das políticas públicas para o meio rural, contam em sua composição com significativo número de agricultores familiares. Contudo, é perceptível que essa vantagem quantitativa por si só é insuficiente para uma efetiva participação democrática, em função da existência de enormes desigualdades nas condições de acesso às informações, nas distintas possibilidades de formação e/ ou capacitação, além das desiguais disponibilidades de tempo, entre outros fatores.

As Leis de instituição dos Conselhos são claras ao afirmar que o exercício da função de conselheiro será "sem ônus para os cofres públicos, sendo considerado serviço relevante prestado ao município" (Lei Municipal n. 467/2001). Contudo, é consenso entre a maioria dos conselheiros que alguns fatores interferem na plena participação dos diferentes membros nos Conselhos. Em entrevista, a Secretária Executiva do CMDRS de Silvânia afirma que o deslocamento, tanto em função do transporte quanto pela distância, além do dia de trabalho e da alimentação, são fatores que dificultam a participação dos agricultores familiares no CMDRS. Segundo ela, normalmente os representantes dos agricultores familiares que pertencem às entidades (STR, SR, Central de Associações, Cooperativa etc.) já tem uma remuneração que garante a participação desses agentes nas atividades dos Conselhos, situação que não é a mesma para os representantes das Associações, da Reforma Agrária, do Jovem Rural, entre outros, os quais, na maioria das vezes, arcam sozinhos com essas despesas. Para elucidar um pouco mais este assunto, veja a opinião de um dos conselheiros:

Nós já construímos muito voluntariamente, mas nem todo mundo pode contribuir voluntariamente. Eu acho que o certo seria pelo menos pagá o dia de serviço da pessoa. Que ela coloca um no lugar dela, a pessoa tem que tirá leite, tem que vim pro Conselho, tem passagem, tem gente que nem tem transporte, talvez o Conselho tinha que viabilizá prá algumas pessoas participar do Conselho o mínimo possível, talvez um dia de serviço. $R \$ 20,00$ (vinte reais) por dia pros conselheiros, por reunião. Eu acho que seria correto. Eu acho que é uma coisa que o Conselho tem que pensar (Conselheiro 4, representante da Cooperativa Agropecuária de Produtores Rurais de Silvânia).

No conjunto de estratégias possíveis de serem utilizadas para sua reprodução, os agentes sociais buscam nos diferenciais de capital, nesse caso representado pelo capital financeiro, uma maneira de se manterem presentes nos Conselhos. Os agricultores familiares buscam mediante a participação se instrumentalizarem para minar o sistema de dominação a que são submetidos.
Caso contrário, o papel da representação pode tornarse comprometido, ou seja, para que se consolidem e se ampliem as práticas da representação e negociação é necessário mais do que espaços públicos democráticos, é necessário que reatualizem-se critérios de igualdade.

Pois, sem a igualdade e como medida de negociação, esta pode-se reduzir a um mero ajustamento corporativo de interesses ou então se resolver no puro jogo de forças (Telles, 1994, p. 96-97).

De outra forma, há a necessidade de construir-se novas competências, pela formação, do acesso a novos recursos de conhecimentos e do acesso às informações para que, os agentes sociais, especialmente os agricultores familiares membros dos Conselhos tenham condições de se reconhecer como sujeitos autônomos e como portadores das competências necessárias para participar ativamente na gestão de políticas para o desenvolvimento rural.

A Agenciarural, por meio da Supervisão de Organização Rural, e a Fundação de Desenvolvimento, Assistência Técnica e Extensão Rural de Goiás (Fundater) são as entidades que normalmente realizam, para os membros dos Conselhos, cursos de Gestão Social com o objetivo de qualificá-los para o exercício da função de conselheiros, em que passam a ter conhecimento sobre Leis, Decretos, Orçamentos e, sobretudo, adquirem noções de cidadania.

Assim, questionados se já haviam participado do curso de gestão social direcionado aos conselheiros, a maioria $(64,6 \%)$ foi enfática em informar que não participou e somente 17 conselheiros $(35,4 \%)$ afirmaram ter participado do curso de formação social. Mesmo que reduzida, houve a participação de alguns membros. Contudo, normalmente esses cursos destinam-se a todos os membros dos Conselhos, de forma indistinta, até mesmo para os representantes do poder público, com conhecimentos diferenciados sobre o funcionamento da máquina governamental. Além disso, mudanças importantes que precisam ser realizadas nos Conselhos, em muitos casos, têm que emergir em meio a muita resistência por parte dos representantes do poder público, fazendo com que ocorram de modo parcial, superficial e menos abrangente, em função dos diferenciais de participação dos diversos agentes envolvidos nos Conselhos.

Os Conselhos, na qualidade de campos, terminam, em muitos casos, por legitimar a cultura dos dominantes, induzindo os dominados a serem cúmplices de sua própria dominação. O que não quer dizer que os dominados não percebam, e até mais facilmente, por sua própria posição, os mecanismos de dominação. Apenas se encontram menos instrumentalizados para uso dessa percepção. Assim, a participação social e a denúncia dos mecanismos de dominação são instrumentos que buscam promover mudanças que afetem as desigualdades sociais e o sistema de dominação. 


\section{Cartografia dos sujeitos sociais instituintes dos conselhos: tessitura de dissensos e consensos}

Procedi à cartografia dos agentes sociais que compõem os CMDRS, ao mesmo tempo em que busquei analisar as práticas sociais dos conselheiros municipais de desenvolvimento rural, como um processo de produção de estratégias nos termos propostos por Bourdieu, por meio da análise dos discursos e da capacidade de intervenção desses agentes sociais nos CMDRS.

O movimento sindical dos trabalhadores rurais, aqui representado pelos Sindicatos dos Trabalhadores Rurais, de composição heterogênea e onde cada sindicalista apresenta traços distintos, é marcado por diversas capacidades de intervenção.

Em Bela Vista de Goiás, as atividades do sindicato pautam-se por ações assistencialistas e pouco afeitas à representatividade dos agricultores familiares. Em Silvânia, o STR, que também se encontra economicamente fragilizado, apresenta-se mais atuante na defesa dos interesses dos agricultores familiares. Busca desenvolver ações de política agrária, previdenciária e trabalhista para os trabalhadores rurais e os agricultores familiares. No CMDRS de Silvânia, é o Presidente do STR que se apresenta como o mais combativo dos conselheiros diante dos embates que se estabelecem e às relações desiguais de poder entre os representantes do poder público e os representantes da agricultura familiar. Constata-se em Silvânia, a existência de uma situação de conflito social entre o Sindicato Rural e o STR pelo monopólio da representação dos agricultores familiares. Deduz-se daí, que o SR, débil em capital social, busca na representação dos agricultores familiares acumular um quantum desse capital com vistas à sua utilização diante da necessidade de lutar em prol das demandas da agricultura patronal.

As cooperativas, presentes em Bela Vista de Goiás e em Silvânia, desenvolvem atividades econômicas similares, porém o perfil de atuação junto aos agricultores familiares apresenta-se diferenciado. Ambas as cooperativas têm o leite como principal produto comercial. Em Bela Vista a Cooperativa busca, pela qualificação dos agricultores familiares, melhorar a qualidade do leite fornecido, com suas ações direcionadas somente a este fim. Suas intervenções junto ao CMDRS pautam-se pelo discurso de procurar aperfeiçoar tecnicamente os agricultores familiares para que estes aumentem seus lucros, no entanto, o que de fato almejam é a melhora qualidade do leite e, assim, aumentar a competitividade e a lucratividade da Cooperativa. Em Silvânia, o trabalho da Cooperativa realiza-se em parceria com a Central de Associações, visto que foi em função desta que aquela foi criada, para ser o braço comercial da Central. As atividades desenvolvidas são bastante diversificadas, além da comercialização do leite, tem uma fábrica de ração e desenvolvem ações produtivas e comerciais com fruticultura e agroecologia junto aos agricultores familiares. A participação da Cooperativa e da Central de Produtores no Conselho, pautada, em princípio, pelo consenso, termina por desqualificar-se. Uma vez que problemas socioeconômicos e políticos originados no Executivo Municipal, se tornam obstáculos à concretização das demandas deliberadas no CMDRS e interferem nas atividades desenvolvidas pela cooperativa junto aos agricultores familiares, os conflitos desnudam-se e os embates então se realizam.

Entre as associações de produtores, presentes nos dois municípios, somente a de Bela Vista de Goiás tem assento específico. No entanto, as inúmeras dificuldades financeiras por que vêm passando, tanto os agricultores familiares quanto suas associações, têm levado os agricultores a se ausentarem dos espaços de realização de atividades associativas e de representação social, o que tem contribuído para uma reduzida inserção social desses agentes dentro do CMDRS de Bela Vista de Goiás. Em Silvânia as associações são representadas no Conselho pela Central de Associações que participa em nome de todas as associações de produtores da região.

Os técnicos da extensão rural, também desmotivados com a precariedade financeira e de recursos materiais a que estão submetidos, desenvolvem de forma precária as atividades de assistência técnica e extensão para os agricultores familiares, priorizando, no entanto, os projetos de financiamento do Pronaf. Com relação à participação dos técnicos no espaço do Conselho, esta se efetiva nos moldes da tradição à qual a extensão sempre se pautou, de tentar submeter os agricultores familiares aos domínios do conhecimento técnico, tal qual como acontecia quando utilizavam os receituários técnicos. Não propiciando a facilitação para que os Conselhos se tornem espaços democráticos de participação social e de gestão de políticas públicas para o meio rural, em especial para os agricultores familiares.

Em relação às ações empreendidas pelo Executivo Municipal, estas delineiam-se pelo caráter antidemocrático e autoritário. A predisposição para uma redistribuição do poder, em que pese a participação quantitativa dos representantes dos agricultores familiares, ainda é incipiente. Um dos pontos movediços é, ainda, a presença dos secretários municipais de agricultura perante a presidência dos Conselhos, que, em muitos casos, dificulta o encaminhamento das demandas junto ao executivo municipal, em função de estar subjugado às suas determinações. Assim, o fato de existir paridade numérica entre os representantes do poder público e dos agricultores familiares por si só não confere legitimidade às deliberações realizadas no âmbito dos Conselhos.

Os recursos financeiros do Pronaf, ao mesmo tempo resultante da luta social dos trabalhadores ru- 
rais, transformaram-se em instrumento de controle social, visto que a racionalidade governamental interfere destituindo as possibilidades de gestão dos recursos públicos por parte dos agricultores familiares.

\section{Conclusão}

Os CMDRS inscrevem-se nas concepções de democracia participativa como espaços privilegiados para um novo padrão de gestão e discussão das políticas públicas, mas que, de fato, delineiam-se como espaços fortemente atravessados por relações de força, de poder e de conflitos sociais. É perceptível que, tanto a ausência de interesse governamental em partilhar o poder, quanto a fragilidade organizacional e a falta

\section{Referências}

ABRAMOVAY, Ricardo. O futuro das regiões rurais. Porto Alegre: Editora da UFRGS, 2003.

BOURDIEU, Pierre. Coisas ditas. São Paulo: Ed. Brasiliense, 1990.

BOURDIEU, Pierre. Escritos de educação. Petrópolis: Vozes, 2002.

CONSELHO NACIONAL DE DESENVOLVIMENTO RURAL SUSTENTÁVEL. Propõe diretrizes e atribuições para a rede de Conselhos de Desenvolvimento Rural Sustentável - CDRS, nos diferentes níveis de atuação. Resolução n. 48, de 16 de setembro de 2004. Disponível em: http://www.pronaf.gov.br/dater/arquivos/legis5.pdf. Acesso em: 13.10.2006.

GUANZIROLI, Carlos E., et al. Agricultura familiar e reforma agrária no século XXI. Rio de Janeiro: Garamond, 2001. IPARDES. Caracterização dos Conselhos Municipais de Desenvolvimento Rural do Paraná: síntese dos principais resultados da pesquisa de campo. Curitiba: Ipardes, 200I.

IPARDES. Caracterização dos Conselhos Municipais de Desenvolvimento Rural - análise comparada - 2000-2002. Curitiba: Ipardes, 2003.

LEOPOLDO DE BULHÕES. Lei n. 467: promulgada em 12 de junho de 2001.

MDA. 2005. Estudo propositivo do Território Estrada de Ferro Goiás: versão preliminar. Disponível em: <http://serv-sdt-1. mda.gov.br/gnc/gnc/ep/estudos/GO_ESTRADADEFERRO.pdf>. Acesso em: 13.04.2007.

MATOS, Aécio Gomes de. Capital social e autonomia. Disponível em: <http://www.nead.org.br/index.php?acao de autonomia dos representantes dos agricultores familiares denotam os Conselhos como espaços em que a participação social ainda apresenta-se bastante incipiente e debilitada e, em muitos casos, a escassez de capital social tem minado a democracia das estruturas institucionais e políticas, reproduzindo e legitimando, com o critério da participação, as relações de dominação pré-existentes.

Mesmo estando fragilizadas a participação social e a capacidade de intervenção dos agentes sociais na gestão das políticas públicas, estes processos estão sendo paulatinamente construídos e (re)construídos, o que permite o descortinar de um campo social bastante fértil para o incremento de novas práticas de gestão social, as quais tenham por objetivo emular a participação das comunidades e o fortalecimento da cidadania, por meio da participação social das mulheres no seio desses espaços. $=\operatorname{artigo} \& i d=1 \&$ titulo $=$ Artigo + do + Mes $>$. Acesso em: 20.11.2005.

MORUZZI MARQUES, Paulo Eduardo. Participação e Pronaf: um estudo do poder, dos atores e dos conflitos em torno dos conselhos municipais de desenvolvimento rural. In: SCHNEIDER, Sérgio; SILVA, Marcelo Kunrath; MORUZZI MARQUES, Paulo Eduardo. (Orgs.). Politicas públicas e participação social no Brasil rural. Porto Alegre: Editora da UFRGS. p. 51-119, 2004.

PUTNAM, Robert D. Comunidade e democracia: a experiência da Itália moderna. Rio de Janeiro: Fundação Getúlio Vargas, 1996.

SCHNEIDER, Sérgio; CAZELLA, Ademir Antônio; MATTEI, Lauro. Histórico, caracterização e dinâmica recente do Pronaf - Programa Nacional de Fortalecimento da Agricultura Familiar. In: SCHNEIDER, Sérgio; SILVA, Marcelo Kunrath; MORUZZI MARQUES, Paulo Eduardo. (Orgs.). Políticas públicas e participação social no Brasil rural. Porto Alegre: Editora da UFRGS. p. 21-47, 2004.

SEPLAN/SEPIN. Disponível em: <http://portalsepin. seplan.go.gov.br/perfilweb/ mostranew.asp $>$. Acesso em: 14.04.2007.

TELLES, Vera da Silva. Sociedade civil e a construção de espaços públicos. In: DAGNINO, Evelina (Org.). Anos 90: política e sociedade nos Brasil. São Paulo: Brasiliense. p. 91-102, 1994.

TOMMASI, Lívia De. A participação nos conselhos paritários: significados e limites. In: Conselhos municipais e políticas sociais. Rio de Janeiro: IBAM/IPEA. p. 78-97, 1997. 


\title{
Public Policy and Women's Social Participation: the Experience of the Municipal Councils for Sustainable Rural Development
}

\begin{abstract}
This work analyses the Municipal Councils for Sustainable Rural Development of the municipalities of Bela Vista of Goiás and Silvânia in the State of Goias. It shows the participation of farmers in making decision and operating the public policies for rural areas. The Councils involve social relationships crossed by conflicts and disputes, with a predominance of the male social participation at the expense of women's, with evidence of marginalization of women in rural areas Brazil. This study examines the social relationships that are established between the various stakeholders involved in these Councils with a special focus on the relations of genders.
\end{abstract}

Key words: public policies; advice managers; social participation; gender.

Data de recebimento do artigo: 30-05-2008

Data de aprovação do artigo: 05-09-2008 